\title{
The Role of the Family in the Socialization of Children
}

\section{Maryam Hosseinzadeh Baferani}

Department of Educational Sciences, Payame Noor University (PNU), Tehran, Iran

\section{Doi:10.5901/mjss.2015.v6n6s6p417}

\begin{abstract}
The main purpose of this research is to study "the role of the family in the socialization of children". The study population was all high school students in District 2 of the city with her parents in the 2014-2015 school year, the sample of 100 participants was selected by stratified sampling method (50 parents and 50 children).Data was obtained through questionnaires (Questionnaire "Schaeffer family" and socialization questionnaire). SPSS software, $t$-test, and descriptive tables were used for data analysis. Results indicate that the amount of love in the family affects the socialization of children. $(p<0.05)$ Control of the family affects children's socialization. $(p<0.05)$ The cold and warm relationships in family affect the socialization of children. ( $p$ $<0.05)$
\end{abstract}

Keywords: family, love, control, cold - warm relationships, socialization

\section{Introduction}

Man being social origin and social aspects of child development constitutes the basis of his human life. Necessary social, psychological fitness, enjoyment of social skills, self-esteem and social adaptability. Undoubtedly, the personality of the community is the social dimension of personality. In a word, family, good character development of children's basic platform. Parents, at least begin from the time that thought in your mind nurture childbearing, educational work. All eyes all walked and everything directly and indirectly voluntary and involuntary them makes the book a lesson and an example to the children and the critical factors of social development. In the process of socialization of children in the family, which forbids parents, imitation and identification of the most important ways of transmitting the values, norms and social customs that are mentioned. In fact, in the family that children learn what is right and what is wrong (Sotoudeh, 2004).

Child characteristics inherited from their parents in this way, parents provide growth and development of children. Parental influence on children is not limited to hereditary aspects, but also in understanding the child's parents in public life and culture also play an important role Family social status, economic situation, opinions, customs, ideals and aspirations of parents and their education level has a lot of influence on children's behavior (Shariatmadari, 1970). Healthy child is born, the highest growth potential, he created at his best, and it has the capacity to be trained in the best way and to achieve the highest perfection; provided that the family should be given the right environment in which to grow. (Atai, 2012)For children from socially desirable growth should benefit from the experience of pleasant social. When the adult patterns because parents always intimate and emotional relationship with the child and establish social balance and vitality of the association and play together, they prepare children to communicate with others and to participate in social activities more. Conversely, children whose parents are not with them but autocratic behavior and ordering another behavior, such experiences are unpleasant and repugnant not show much desire to connect with others. Anxiety, shyness, anger and aggression among parents and children could be socially desirable growth of pests. To encourage children to develop their social connections have sweet memories of their relationship with their parents remain in their minds so that social satisfaction for the positive relationship and interaction with others. According to what was said to be the family's role in children's socialization realized. This study aims to investigate the role of the family in the socialization of children in 2014.

\subsection{Problem Statement}

We are social beings, and we are able to continue living in the community with others. The lack of compatibility and synergy with other young people grows more complete due to lack of them. It would be a long-term binding disturb social order. Having the right relationships, healthy and positive with others can be a key to development and human perfection. Socialization process that people with the values, beliefs and standards of behavior that culture expects them to learn. 
(Yasaei, 2001) family is a small community that one of the aims is the socialization of children Family learning center person; for one, many of the family learns social behavior, such as respect for the rights of others, having good or evil traits and environmental compatibility of family and others. For the social development of children naturally be complete, certain conditions must prevail in the family environment, which are briefly discussed below.

One must in a family environment, a sense of peace and security and ensure that the love and respect of others. When someone in the family is about love, social relations will be strengthened further, but if a family environment with fear and anxiety, he joined the humiliation and hatred, the vengeful and cynical times, and certainly in the social connections will be a failure. The behavior of parents in child development and social education is very effective. If parents constantly argue and talk constantly of separation and divorce, the socialization of the child would be severely compromised. In these situations, children suffered from anxiety and fear, and always concerned that fights and disputes occur between parents. This practice has very bad effects on children's mental and social fields and provides diversion and delinquency.

In addition, the children of these families after marriage and family, his parents followed the ugly behavior and their wives behave in the same style.

This issue in addition to severe psychological distress for families, in the long term may even lead to ruin societies. This study aims to investigate the role of the family in the socialization of children in 2014. The role of love, family relations, social control are examined in children.

\section{Literature Review}

Mahboubeh Delavari (2011) examined ways of parenting and found that different parenting styles in families with different effects on the formation of character and upbringing and development of social, emotional, intellectual, emotional and children.

Iqbal Zarei (2011) examined the relationship between parenting styles and adolescent risky behaviors committed by Kloninger scale and found that the parenting style of parents, children constructive and destructive behavior because of the leading role and the importance of parents There is a significant relationship. Therefore, notifying parents and family education campaigns to foster healthy individuals in the community is very important and relevant organizations should play a more active role in this regard.

Kalantari, Molavi, and Tavasoli (2005) examined the "relationship between parenting styles and behavioral disorders in preschool children in the city".

The results showed that increasing dependence scores in the questionnaire of parenting styles dependent independence, behavioral disorders in children increased significantly with increasing severity scores- the relaxation of the questionnaire of parenting styles, behavioral disorders in children significantly increases.

Karimi (2001) "the relationship between religious attitudes and practices parenting attitudes girls" put into research. Statistical analysis showed that the attitude of parenting style (authoritative) achievement (grade point average and score Sciences) students and a significant positive correlation between attitude parenting (authoritarian) mother, there is a significant negative relationship.

Among attitudes parenting styles (authoritative, loose, tyranny) mother and achievement (grade point average, the science and math score) were observed relationship.

Mehrabizadeh (1997) in a study entitled "The effect of the emotional atmosphere of the family in the socialization of children in the first year students in Kerman tips" that the socialization of children in the socialization of children of dictatorship and democracy is more permissive. Also points out that the more permissive socialization of families and the families of the dictator is not a significant difference.

Shariat (1997) studied the "Compare social development and academic achievement of children of broken families with children joined up". The results showed that children from disrupted families compared with children of coherent significantly in terms of social development are at a lower level.

Ghamsari (1993) examined the "social role of the family in children". The results showed that the more parents talk with their children and to have control and they teach their children to be better community. Nailing (2010) in a longitudinal study about "the effect of family and education on the academic results of different groups of students with demographic variables and inputs their school" came to the conclusion that the academic achievement of students with multiple components of the family as beliefs and expectations of parents, disciplinary actions and interventions, parents, family emotional environment governing the family and available resources are linked (Quoted from Haydar Weiss, 1999). Secker et al (2009) in their study as "social skills and behavior on the issue of foster preschoolers with cognitive styles thinking- impulsive" It concluded that impulsivity of children in social situations and social participation of less efficient 
Children are reflective of the behavior of children in situations of problem solving and attention deficit hyperactivity example of aggressive behavior (Quoted from Haydar Weiss, 1999).

Ropnrin et al. (2006) in a study entitled "The effect of parenting styles, parents' educational interventions for children at home and school communication with parents on children's social behavior and academic skills" to conclude that parenting styles, authoritarian father acquired skills the extent of the child's vocabulary is negative, while the authoritarian style of his father and academic engagement with the child at home and constant contact with the child's school life skills and social behavior of children with growth positively correlated, in the case of women in the study found that authoritarian parenting style of mothers with children social behavior has a negative relationship, while women who have an ongoing relationship with your child's school, children from higher social development. (According to Zarei, 2011)

Rubin and Mills (2005) in a study titled "Maternal beliefs about social behavior and three children sides' conformist atmosphere (passive), aggressive and non-preschool" came to the conclusion that mothers than mothers of normal children believe with drawn these mothers are also more likely than mothers of normal children in their children a sense of guilt and shame were maladaptive behaviors and these behaviors were attributed to natural causes. Mothers to their children more aggressive for teaching social skills instruction methods were used and they were indifferent toward maladaptive behaviors. (Quoted from Mehrabizadeh, 1997)And even this condition may affect the relationship between the candidate and partner. (According to Zarei, 2011)

Beasley et al (1999) in a study entitled "The impact of parents' relationships with their peers in preschool children" to the conclusion that parents who are intimate with their children and often for their children to the game with their peers and about their children solve disputes with friends, they are skillful recommendations, with children who have many friends and are more social skills and are able to inhibit the negative emotions. And generally come along very well with his peers. (According to Zarei, 2011)

Richter et al. (1993) in the framework of the vulnerability "of the relationship between parents and adaptive behavior in adulthood," the studied. The results indicate that childhood social experiences, especially in relations parent child directly vulnerability to mental disorders in later life and indirectly affect the status through which individuals acquire the adaptive strategies. Parental rejection and radical support significantly correlated with adaptive behavior. (Quoted from Mehrabizadeh, 1997)

Lamborn et al. (1991) research in the field of "adequate and consistent pattern among young families authoritarian, authoritative, neglectful and extremism among young people 18-14 years old in 4100 with four sets of behavioral consequences, including psychological growth academic achievement, internal anxiety and behavioral problems "to the results found that adolescents from authoritative families are educated and have significant merit. Teenagers with their parents as authoritarian, extremist were described, at all scales, tended to moderate their score between the groups was negligent authoritative and generally the size difference between authoritative and neglectful families In terms of academic achievement and other cases respectively. (According to Zarei, 2011)

Arnas (1991) in a study titled "marital discord parents in child development and behavior of the Fathers" that different parents in raising children leads to behavioral problems in children and leads to behavioral problems of a more to marital adjustment of the. (Quoted from Haydar Weiss, 1999) Makobi and Martin (1983) showed that the receptive parents control children's behavior.Non-receptive parents to allow children to want to do what parents are willing to accept to accept children and meet their needs. Indifferent parents reject their children and consider first their demands. (According to Schiffer, 1996) Bam rind's study (1978) showed that children whose parents are warm and accepting more happy, self-reliant and show more autonomy, self-esteem and high skills.In contrast, parents caring for children of different ages have negative effects, such as anxiety, agitation, anxiety, social dysfunction and low moral growth of their children. (Bam rind, 1978)

\section{Hypotheses}

1. The love of family influence affects the socialization of children.

2. The social control of family affects the children's socialization.

3. The amount of cold and warmth in family relationships affect children's socialization.

\section{Materials and methods}

The methodology of the research is a survey. Data was obtained through questionnaires (Questionnaire "Schaeffer family" and socialization questionnaire). Research community investigating all high school students in District 2 of the city along with their parents were in 2014-2015 school year. 100 (including 50 parents and 50 children) of high schools using 
stratified sampling method were selected. SPSS software, descriptive tables, t-test were used for data analysis.

\section{Findings}

Central variable and dispersion of the research variables

Table 1 Indices of central and dispersion of variables. Results of the table show that the socialization of the sample is lower than the normal population. The degree of control and the affection is moderate.

\begin{tabular}{|c|c|c|c|c|}
\hline socialization & Relationship & Control & Passion & Variables \\
\hline $87 / 86$ & $66 / 64$ & $86 / 124$ & $63 / 40$ & Scale \\
\hline $8 / 65$ & $8 / 68$ & $20 / 46$ & $15 / 752$ & Mean \\
\hline
\end{tabular}

\subsection{First hypothesis: the love of family influence in the socialization of children.}

Table 2. Effect of affection in the family affects the socialization of children

\begin{tabular}{|c|c|c|c|c|c|}
\hline Level of sig. & $\mathrm{t}$ & D.F. & S.D. & Mean & Variable \\
\hline $0 / 00$ & 49 & $-14 / 095$ & $14 / 208$ & $-25 / 46$ & Passion - socialization \\
\hline
\end{tabular}

Results of the table show the amount of love affects the children's socialization. The level of significance which is obtained is smaller than the considered level (0.05). As a result, the first hypothesis is confirmed.

\subsection{The second hypothesis: the social control in the family affects the children's socialization.}

Table 3. The effect of social control of the family in the children's socialization

\begin{tabular}{|c|c|c|c|c|c|}
\hline Level of sig. & $\mathrm{t}$ & D.F. & S.D. & Mean & Variable \\
\hline $0 / 00$ & 49 & $16 / 546$ & $17 / 829$ & 38 & Control- Socialization \\
\hline
\end{tabular}

Results of the table show that the level of social control in the family affects children. The level of significance which is obtained is smaller than the considered level (0.05). As a result, the second hypothesis is confirmed.

\subsection{The third hypothesis: the family relationships affect the children's socialization.}

Table 4. The family relationships affect the children's socialization

\begin{tabular}{|c|c|c|c|c|c|}
\hline Level of sig. & $\mathrm{t}$ & D.F. & S.D. & Mean & Variable \\
\hline $0 / 00$ & 49 & $-15 / 44$ & $11 / 391$ & $-22 / 220$ & Relationship-Socialization \\
\hline
\end{tabular}

Results of the table show the amount of cold and warmth in family relationships has an impact on the socialization of children. The level of significance which is obtained is smaller than the considered level $(0.05)$. As a result, the third hypothesis is confirmed.

\section{Results}

This study aimed to investigate the role of the family in children's socialization.

And cold and heat control as well as the role of love and family in the socialization of children were studied. Using SPSS software and t-test results were as follows:

\subsection{The amount of love in the family socialization of children affected. $(p<0.05)$}

The first hypothesis was confirmed. 
This finding by Beasley et al (1999) observed that "parents who are intimate with their children and often for their children to the game with their peers and to resolve disputes with their friends, their children, their recommendations skillful They have a lot of friends with children who had higher social skills and are able to control their negative emotions

Generally, they come along very well with his peers ".And Bam rind's findings (1978) that the "children whose parents have warm relationships, they are more happy, self-reliant and they show more autonomy, self-esteem and high skills.

In contrast, parents caring for children of different ages have negative effects, such as anxiety, agitation, anxiety, social dysfunction and low moral development of their children "matches.

\subsection{The level of social control in the family affects children. $(P<0 / 05)$}

The second hypothesis was confirmed. This result is consistent with the findings of Ghamsarii (1993) which was found "the more parents talked with their children and to have the control they teach, their children are better in community."

Nailing (2010) found that "academic achievement and social growth of students with multiple components, such as beliefs and expectations of parents, family, disciplinary actions and interventions, parents, family emotional environment governing the family and available resources are linked.".

\subsection{The amount of cold and warmth in family relationships affect children's socialization. $(p<0.05)$.}

The third hypothesis was confirmed.

This result is consistent with the findings of the Law (1997) observed that "children compared to children of families torn apart coherent significantly in terms of social development are at a lower level".

And Kinsey's findings Fogel and Garich (2004) found that "the family that there are conflicts between parents and children control the level of verbal and verbal and physical fight was hard, in their relationships with others in large quantities such behaviors occur and even the condition may affect the relationship between the candidate and partner". The findings of Arnas (1991) which received a "difference of parents in raising children leads to behavioral problems in children and leads to major behavioral problems than marital compatibility" matches.

\section{Suggestions}

In all theories of education, family and parents are the core of education. The responsible institution for the general population is responsible for the family. Under normal circumstances in the family and the parents of children in the early years of life remain, the most important factor in building the personality of the child's parents and family environment are considered. And he has an important role in learning. Children living conditions on how they affect growth. A child in a difficult environment in terms of nutrition and health in terms of lives, no doubt in the process of socialization will be disrupted. A child in a noisy and restless and aggressive people living with probably emotionally disturbed and aggressive behavior of shows.

Media, cultural and educational centers, as well as counseling and psychotherapy must first great attempt at informing the family of the needs and problems of children and adolescents and, if necessary, to help them take them.

Educating parents in different ways, especially through family education classes and continually guided by experts, are required in this regard. Families should learn:

- To be aware of their role model and understand the effects of their behavior is not unique to the present time. Children or adolescents whose parents are not incompatible, in the future will play an appropriate role as wives and parents.

- To avoid family conflict and debate each parent to their obligations to respect the rights of others and be useful to him.

- The location and age of their children, especially adolescents, according to his needs and desires of their own and other children to know who he is and must be experienced to some extent, freedom and life.

- Of constant and imperative to avoid him.

- Family members be either indifferent or hostile to their encounter with each other.

- Teenage appropriate for the type of family identity that while its members are interrelated, each one independent.

- Discrimination among children away from their family environment. 
- Feelings of rejection during adolescence leads to worthlessness, despair, hopelessness, depression and even suicide can be.

- To consider the fact that more children with parents replication and internalize their values that they like and have good relations with them.

- The growth of delinquency, neglect of family, dismissive, with unstable and harsh discipline and a family in which the victim and the crime is done by parents or siblings, plays an important role. Therefore, to avoid the above methods in dealing with children and adolescents and the lack of punishment which causes unwarranted aggression and anti-social acts in the direction of greater control is necessary. In the case of acts contrary to the separation of families with children, a healthy environment be provided for him.

- Some slight disagreement with regard to divorce, emotional and behavioral problems of homelessness and do not provide for their children.

- Also, if the divorce was necessary and the value it was diagnosed more than a continuation of a normal life, training to deal properly with children need to mitigate the effects of divorce are received.

- The contradictory behavior and avoid having ambivalence with their children. Many parents, however, who wish to be independent teenager cannot accept manifestations of independence and at the same time he wants to have his affiliation, this attitude leads to anger, distrust, and even psychiatric problems such as schizophrenia provides.

- Instead of imposing intolerable dry conditions and controls excessive, humiliation, blame, or corporal punishment explain to young people what the consequences of his behavior. Otherwise we will treat teen bullying parents.

- If the parent-adolescent relationship is unfavorable, to the problem, young people will be on their own. This will be the cause of many moral and behavioral problems.

- Conscientious parents are sensitive to the issues your teen realize your mood changes, understand anxiety and depression cases are his and if it continues to consider remedies come over. It is good about normal and abnormal behaviors known to them to take necessary action at the right time.

\section{References}

Ataei, Maliheh (2012), investigating the relationship between parenting styles and children's behavioral problems in Isfahan in 2012, the general thesis of psychology, University of Payam Noor

Bassis, Michael, 1991, Sociology, New York Mc.Grow.

Baumrind, d. (1978).Parental disciplinary patterns and social competence in children. Youth and society, 9(3).239-276.

Baumrind, d. (1971).current patterns of parental authority. Developmental psychology monographs, 4, (1), 1-03.

N. M. R. Beasley, A. M. Tomkins, A. Hall, C. M. Kihamia, W. Lorri, B. Nduma, W. Issae, C. Nokes and D.A. P. Bundy, (1999). The impact of population level deworming on the haemoglobin levels of schoolchildren in Tanga, Tanzania, Tropical Medicine and International Health, volume 4, no 11, p.p. 744-750,

D.A. P. Bundy1 Delavar, A. (2001), Methods in Educational Sciences, Tehran: growth

Delavari, M. (2011), parenting styles, Tahoura Journal, No. 7, P. 40-13

Fadaei, Neda (2009), the relationship between maternal employment and social development of children, of women and family studies, Issue V, P. 86-67

Ghamsarii, Ali Akbar (1993), the role of the family in the socialization of children, martyr Beheshti University master's thesis

Henry Masen, Powell et al. (2001) and the growth of the child's personality, translation:

MahshidYasaei, Tehran: Markaz

Heydar Weiss, N. (1999), social factors an effective student participation in extracurricular activities schools Region 9 Education in Tehran, Allameh Tabatabai University master's thesis

Kalantari, Mehrdad, Maulavi, Hussein, Tavasoli (2005), investigating the relationship between parenting styles and behavioral disorders in preschool children in the study, Journal of Knowledge and Research in Applied Psychology, 24, P. 68-59

Karimi, Monireh (2001), the relationship between religious attitudes and practices

Parenting attitudes girls MA thesis University.

Lamborn, S.D., Mounts, N. S., Steinberg, L., \& Dornbusch, S. M. (1991).Patterns of competence and adjustment among adolescents from authoritative, authoritarian, indulgent, and neglectful families. Child Development, 62, 1049-1065.

Mehrabi, Golpar (1997), The effect of the emotional atmosphere of the family in the socialization of children in the first year students of Kerman city, MS Thesis Faculty of Psychology and Educational Sciences, AllamehTabatabai

Shaffer,David,1996,Development Psychology Childhood andA DOLESCENCE,grove.

Shariat, Fahimeh (1997) compared the academic achievement and social development of children, families torn apart with children in an integrated, Shiraz University master's thesis 
Shariatmadari, Ali (1970), Educational Psychology, Tehran: Amir, the eleventh edition Sotoudeh guidance of Allah and colleagues (2004), sociology key concepts, Tehran: Avay-

E Noor, Second Edition

Zarei, Iqbal (2010), the relationship between parenting styles with adolescents commit risky behaviors on the scale Kloninger, Journal of Shaheed Sadoughi University of Medical Sciences, High Risk Behavior Conference, Volume 18, Number 3, Suppl.1, P. $220-224$ 